\title{
How to Make Money in Telehealth
}

Milton Chen

Editor's note: This article is adapted from a lecture by Dr. Milton Chen, Founder and CEO of VSee, in July 2016 during the first-annual Future of Health: Telemedicine and Al summit in Ho Chi Minh City, Vietnam.

Telehealth's potential to improve lives is huge. But the potential to make money from telehealth is not so clear. After all, the operational costs for healthcare are growing faster than its revenue. The expense of health IT and moving to electronic records has driven many physicians to leave their private practices. When we add new technologies into the mix, the costs go up even higher. How can enterprising businesses take advantage of telehealth without going broke?1

Telehealth's potential to improve lives is huge. But the potential to make money from telehealth is not so clear.

Companies like Doctor on Demand, Amwell, MDlive, and Teledoc made big splashes when they arrived on the scene. $\stackrel{?}{ }$ These direct-to-consumer services offer inexpensive video consultations to the general public. But whether their business model is sustainable has not become clear. $\underline{3}$ In order to keep their costs low, companies like Doctor on Demand must make hard decisions that may include compromising in other areas. However, in healthcare, far more than dollars are at stake. Experts and doctors debate which systems are fiscally responsible without compromising patient care. $\frac{4}{4}$

\section{Two Examples}

Here are two examples of yet unrealized potential (FitBit) and a failed effort (HealthSpot) to achieve fiscal success in telehealth. 


\section{FitBit}

FitBit had a great start, but they'll run into trouble in the long term unless they can solve the user adoption issue-where people continue to use Fitbit after the novelty wears off.

FitBit should evolve into a full-scale healthcare company in order to unlock the value of wearables for healthcare. Otherwise FitBit is in danger of going the way of GoPro-a cool novelty gadget for a little while, but one that offers little sustained value to drive repeat purchases.

\section{HealthSpot and the Health Kiosk Scenario}

Within the next five years, we'll see telehealth kiosks everywhere. Imagine talking to a doctor at your convenience from an easy-to-use kiosk at work, in a grocery store, or a pharmacy.

But HealthSpot, the pioneer in this space, failed despite raising around $\$ 50 \mathrm{M}$ of investment. HealthSpot used Vidyo, which is so complex and expensive that it broke the HealthSpot business model. Kiosks will need to be very inexpensive_less than $\$ 5,000$ per kiosk.$_{-}^{5}$ [Editor's note: See Rajeev Mudumba's in-depth review of HealthSpot elsewhere in TMT.]

\section{Patient Monitoring at Home}

One of the next big businesses will be telemedicine remote health-monitoring patients' health in their home. Examples include post-surgery and chronic care management. This emerging field could potentially save millions by giving providers instant access to real-time patient data, even while patients are at home. But the companies trying to make it in chronic care are discovering that the available hardware and software solutions are too complex for many consumers.

\section{Post-Surgical Monitoring}

One relatively unexplored but high potential area is monitoring patients after surgery, because only two simple devices are necessary in many cases: a blood pressure cuff and a pulse oximeter. Those two devices provide the vital data that doctors need to monitor their patients. Together they cost less than $\$ 150$. 
Bottom line: video by itself is not sufficient for delivering quality healthcare. To make a real diagnosis, both video and medical devices are needed to achieve successful telemedicine program implementation. The company that figures out how to get affordable devices and simple software into the hands of consumers is the company that will win.

\section{Elder Care}

With the mass retirement of baby boomers, elder care is becoming a big field for telehealth. One company in this space is called GrandPad. $\underline{6}$ They raised a lot of venture capital, but their approach assumes that senior citizens can't handle technology, so GrandPad "dumbs down" the internet experience. A better approach would be to maintain customers' dignity and address them as smart adults through telemedicine process improvement achieved by creating an easy on-ramp to technology.

\section{Health Apps}

Many entrepreneurs assume that they can simply release a new health app and make a lot of money. Right now there are over 165,000 health apps in the App Store; but only a small fraction has user traction. $\frac{7}{}$ The reason is that any health app used in isolation will probably fail. A health app should be integrated into a larger ecosystem, as part of a holistic medical experience.

What about an Uber for healthcare? 5 It's true that Uber has been very good for transportation. But the Uber model of matching customers with the first available provider is too impersonal for healthcare. After all, most people have a favorite doctor they trust and have been seeing for years. That's why there will never by an Uber for healthcare.

\section{Stress and Wellness}


Stress and wellness are the most unexplored fields that could experience significant growth. Health As We Age ${ }^{8}$ and Fruit Street are two examples of companies that are exploring the employee wellness space. $\underline{9}$

Up to now, consumer companies like Weight Watchers held a monopoly on wellness. And they'll probably continue to be successful. But what if a health organization, with all their doctors and medical expertise, entered the wellness industry and compete with Weight Watchers? They could make a dramatic impact, not to mention a lot of money.

\section{The Bottom Line}

Dr. Alan Pitt, Chief Medical Officer at Aviza and attending physician and Professor of Neuroradiology recently said, "Telehealth is bringing healthcare into the digital age and it is up to IT leaders to make the transition seamless."10

That's true, but the secret to a successful transition from an entrepreneurial perspective is to improve patients' health through fiscally sensitive interventions.

Today everyone recognizes that telehealth is the key, but opening the lock leading to optimal care is elusive. The challenge is for enterprising businesses and entrepreneurs to integrate telehealth without going broke.

Dr. Chen is CEO of VSee, a company making telehealth an everyday experience by combining HIPAA video chat, device integration and health data visualization, and medical work flow including reimbursement.

\section{References}

1. Akanksha Jayanthi. Health IT costs exceed $\$ 32 k$ per physician per year. Becher's Health IT and CIO Review. 2016. URL: http://www.beckershospitalreview.com/healthcare-information-technology/healthit-costs-exceed-32k-per-physician-per-year.html. Accessed 8/20/16. 
2. Anne. Doctors on demand-telehealth services to video call your doctor now. VSee. 2016. URL: https://vsee.com/blog/doctor-on-demand-video-call-doctortelehealth-app/. Accessed 8/20/16.

3. Milton. Is Rock Health wrong? Why there is no Uber for Healthcare. 2016. URL: https://vsee.com/blog/why-there-is-no-uber-for-healthcare/. Accessed 8/20/16.

4. Madigan R. Doctor's dilemma: Physicians consider ways to thrive economicallyand sometimes even to survive. Miami Herald. 2014. URL: https://vsee.com/blog/why-there-is-no-uber-for-healthcare/. Accessed 8/20/16.

5. Milton. Three reasons why HealthSpot died. VSee. 2016. URL: https://vsee.com/blog/three-reasons-why-healthspot-failed/. Acessed 8/20/16.

6. GrandPad. GrandPad tablet for seniors. URL: https://www.grandpad.net. Accessed 8/20/16.

7. Misra S. New report finds more than 165,000 mobile health apps now available, takes close look at characteristics \& use. iMedicalApps. 2015. URL: http://www.imedicalapps.com/2015/09/ims-health-apps-report/. Accessed 8/20/16.

8. HAWA. Where wellness meets healthcare. 2016. URL: http://www.healthasweage.com. Accessed 8/20/16.

9. Nina. VSee partner HAWA brings wellness to employee healthcare. VSee. 2016. URL: https://vsee.com/blog/vsee-partner-hawa-brings-wellness-to-employeehealthcare/. Accessed: 8/20/16.

10. Pott A. Tips for getting telehealth across the finish line. HIT Leaders and News.com. URL: http://www.hitleadersandnews.com/tips-for-getting-telehealthacross-the-finish-line/. Accessed: 8/20/16.

Tags: FitBit, Fruit Street, GrandPad, health apps, Health As We Age, health kiosk, HealthSpot, how does telehealth enhance the doctor patient relationship, Milton Chen, patient monitoring, post-surgical monitoring, stress and wellness, telehealth and telemedicine, telemedicine process improvement, telemedicine program implementation, telemedicine remote health, Uber, VSee, what is telemedicine and how does it work 
1679c. Chen.

https://doi.org/10.30953/tmt.v1.83

Page 6 of 6 